\title{
Case- fatality rate in COVID- 19 patients: A meta- analysis of publicly accessible database
}

Souvik Maitra $^{1}$, Mansij Biswas ${ }^{2}$, Sulagna Bhattacharjee ${ }^{1}$

1 Department of Anaesthesiology, Pain Medicine \& Critical Care, All India Institute of Medical Sciences, New Delhi

2 Medical Advisor, Boehringer Ingelheim India

Corresponding Author:

Dr. Mansij Biswas MD,

Email id: doctor.mansij@gmail.com

Keywords: COVID-19; SARS-CoV-2; novel coronavirus; epidemiology, mortality rate 


\begin{abstract}
A novel coronavirus was reported in Wuhan, China in December 2019 to cause severe acute respiratory symptoms (COVID- 19). In this meta-analysis, we estimated case fatality rate from COVID- 19 infection by random effect meta-analysis model with country level data. Publicly accessible web database WorldOMeter (https://www.worldometers.info/coronavirus/) was accessed on 24th March 2020 GMT and reported total number of cases, total death, active cases and seriously ill/ critically ill patients were retrieved. Primary outcome of this meta-analysis was case fatality rate defined by total number of deaths divided by total number of diagnosed cases. Pooled case fatality rate $(95 \%$ CI) was 1.78 (1.34- 2.22) \%. Between country heterogeneity was 0.018 (p<0.0001). Pooled estimate of composite poor outcome (95\% CI) was 4.06 (3.24- 4.88) \% at that point of time after exclusion of countries reported small number of cases. Pooled mortality rate $(95 \% \mathrm{CI})$ was 33.97 (27.44- 40.49) \% amongst closed cases (where patients have recovered or died) with. Meta regression analysis identified statistically significant association between health expenditure and case fatality rate $(\mathrm{p}=0.0017)$.
\end{abstract}




\section{Background}

A novel coronavirus was reported in Wuhan, China in December 2019 to cause severe acute respiratory symptoms (COVID- 19) [1]. Subsequently, this viral outbreak was reported in 197 countries and one international ship on $24^{\text {th }}$ March 2020. A wide range of mortality rate was reported from this viral illness and World Health Organization reported mortality rate of $3.4 \%$ on $3^{\text {rd }}$ March 2020 [2].

\section{Objectives}

In this meta-analysis, we estimated 'case fatality rate' from COVID- 19 infection by random effect meta-analysis model with country level data.

\section{Methods}

Publicly accessible web 'WorldOMeter' (https://www.worldometers.info/coronavirus/) was accessed on $24^{\text {th }}$ March 2020 GMT and reported total number of cases, total death, active cases and seriously ill/ critically ill patients were retrieved. Primary outcome of this meta-analysis was 'case fatality rate' defined by total number of deaths divided by total number of diagnosed cases. Secondary outcomes were mortality rate amongst closed cases (where patients recovered or died) and proportion of composite poor outcome (defined by the number of patients died or critically ill). Metaregression analysis was performed to identify association between population density, health expenditure (percentage of GDP) and percentages of patients over $65 \mathrm{y}$ age with mortality. Between country heterogeneity $(\tau)$ was estimated by restricted maximum likelihood method and $95 \%$ prediction interval of pooled mortality were reported [3]. Countries reporting small number of cases ( $<100$ on $24^{\text {th }}$ March 2020) were excluded from analysis; however, sensitivity analysis was planned with including them. Association between mortality and clinical characteristics of the patients were assessed by mixed effect meta-regression model. 
medRxiv preprint doi: https://doi.org/10.1101/2020.04.09.20059683; this version posted April 22, 2020. The copyright holder for this preprint

All analyses were conducted in metafor package in $\mathrm{R}$ ( $\mathrm{R}$ version 3.6.1; $\mathrm{R}$ Foundation for Statistical Computing, Vienna, Austria).

\section{Results}

At the time of database access, 422582 patients were infected with COVID-19 with 18891 patients have died till that point of time. At that point of time 13269 patients were critically or seriously ill. Pooled case fatality rate $(95 \% \mathrm{CI})$ was $1.78(1.34-2.22) \%$ with $\mathrm{I}^{2}=99.18 \%$. Between country heterogeneity $(\tau)$ was $0.018(\mathrm{p}<0.0001)$. Sensitivity analysis was performed by exclusion of one country at times and pooled estimates of crude fatality rate remained mostly similar. Another sensitivity analysis was performed including countries where reported total number of cases were less than 100 , and estimated case fatality rate $(95 \% \mathrm{CI})$ was $1.77 \%(1.44-2.14) \%$ with $\mathrm{I}^{2}=97.75 \%$. Significant amount of publication bias was identified by regression test both with $(\mathrm{p}<0.0001)$ and without $(\mathrm{p}=0.0017)$ including countries will small number of cases. Pooled estimate of composite poor outcome (95\% CI) was 4.06 (3.24- 4.88) \% with $\mathrm{I}^{2}=99.44 \%$ at that point of time after exclusion of countries reported small number of cases.

Pooled mortality rate (95\% CI) was 33.97 (27.44- 40.49) \% amongst closed cases (where patients have recovered or died) with $\mathrm{I}^{2}=99.88 \%$ [figure 1]. Meta regression analysis identified statistically significant association between health expenditure and case fatality rate $(\mathrm{p}=0.0017)$ [figure 2].

\section{Discussion}

We have found a pooled mortality rate of $1.77 \%$, which was less than WHO reported death rate of $3.4 \%$ but similar to the first published report of mortality from Wuhan, China. [1] Our pooled estimate of composite poor outcome was around $4 \%$, which was similar to the previous report from China. Another important finding is that presence of a significant heterogeneity and publication biases in the pooled analysis. Underreporting from different 
countries and heterogenous testing strategy and quality of care are probably reason thereof. Estimation of mortality rate at the time of outbreak is difficult because there are always a proportion of newly diagnosed cases where clinical outcome (death or recovery) is yet to happen. Secondly, total number of diagnosed cases depends upon the diagnostic strategy of the country and proportion of asymptomatic cases. Surprising high mortality were obtained when only closed cases were used in denominator; however, true mortality rate is expected to be smaller as a large number of suspected patients were not subjected to laboratory confirmation. So, actual mortality from COVID- 19 is difficult to estimate at this point of time and it could higher than current estimation.

References

1. Guan WJ, Ni ZY, Hu Y, et al. Clinical Characteristics of Coronavirus Disease 2019 in China [published online ahead of print, 2020 Feb 28]. N Engl J Med.

2. WHO Director-General's opening remarks at the media briefing on COVID-19 - 3 March 2020 - World Health Organization, March 3, 2020

3. Deeks JJ, Higgins JPT, Altman DG (editors). Chapter 9: Analysing data and undertaking meta-analyses. In: Higgins JPT, Green S (editors). Cochrane Handbook for Systematic Reviews of Interventions Version 5.1.0 (updated March 2011). The Cochrane Collaboration, 2011. Available from www.handbook.cochrane.org.

Figure Legends

Figure 1: Forest plot showing estimated mortality rate amongst closed cases at country level and pooled estimate of mortality rate.

Figure 2: Bubble plot showing association between health expenditure (expressed as percentages of GDP) and log of case fatality rate. 
Countries

China Italy USA

Spain Germany Iran France Switzerland S. Korea UK

Netherlands Austria

Belgium Norway Canada Portugal

Australia Sweden Brazil Israel

Turkey Malaysia Denmark Czechia Ireland Japan Luxembourg Ecuador Pakistan Chile Poland Thailand Romania Finland Saudi Arabia Greece Indonesia Iceland Singapore South Africa Philippines

India Qatar Russia Slovenia Panama Peru Egypt Bahrain Hong Kong Argentina Croatia Colombia Estonia Mexico Lebanor Iraq

Dominican Republic Serbia Algeria Armenia UAE ( Bulgaria Taiwan Lithuania New Zealand Slovakia Latvia Kuwait

Uruguay

San Marino

Hungary Costa Rica Morocco

Bosnia and Herzegovina Andorra Jordan North Macedonia

Vietnam Moldova Cyprus Albania Faeroe Islands Tunisia Burkina Faso Malta

Brunei. Ukraine Sri Lanke

Overall $\left(I^{\wedge} 2=9988 \%, P<0.001\right) \quad 0.340 \quad(0.274,0.405) \quad 18827 / 126496$

Death

$0.043(0.041,0.044) \quad 3277 / 76436$ $0.450(0.442,0.458) \quad 6820 / 15146$ $0.673(0.646,0.700) \quad 778 / 1156$ $0.441(0.429,0.453) \quad 2991 / 6785$ $0.046(0.039,0.053) \quad 159 / 3449$ $0.178(0.171,0.186) \quad 1934 / 10847$ $0.251(0.238,0.264) \quad 1100 / 4381$ $0.482(0.421,0.544) \quad 122 / 253$ $0.033(0.027,0.039) \quad 120 / 3627$ $0.758 \quad(0.722,0.793) \quad 422 / 557$ $0.993(0.983,1.000) \quad 276 / 278$ $0.757(0.619,0.895) \quad 28 / 37$ $0.209(0.176,0.242) \quad 122 / 583$ $0.667(0.449,0.884) \quad 12 / 18$ $0.188(0.123,0.254) \quad 26 / 138$ $0.600(0.471,0.729) \quad 33 / 55$ $0.063(0.021,0.106) \quad 8 / 126$ $0.714(0.596,0.833) \quad 40 / 56$ $0.958(0.902,1.000) \quad 46 / 48$ $0.054(0.000,0.113)$ $0.989(0.958,1.000)$ $0.080(0.043,0.118)$ $0.970(0.911,1.000)$ $0.231(0.002,0.460)$ $0.583(0.304,0.862)$ $0.131(0.095,0.168)$ $0.571(0.312,0.831)$ $0.900(0.793,1.000)$ $0.280(0.104,0.456)$ $0.105(0.000,0.243)$ $0.909(0.739,1.000)$ $0.071(0.004,0.139)$ $0.132(0.062,0.201)$ $0.091(0.000,0.261)$ $0.034(0.000,0.101)$ $0.408(0.271,0.546)$ $0.647(0.545,0.749)$ $0.038(0.000,0.089)$ $0.013(0.000,0.030)$ $0.100(0.000,0.363)$ $0.636(0.509,0.763)$

$3 / 56$

$44 / 44$ $16 / 199$ $32 / 33$ $3 / 13$ $7 / 12$ $43 / 328$ $8 / 14$ $27 / 30$

$7 / 25$ $2 / 19$ $10 / 11$ $4 / 56$ $12 / 91$ $1 / 11$ $1 / 29$ $20 / 49$ $2 / 53$ $2 / 158$ $0 / 4$
$35 / 55$ $0.043^{\text {It is made available under }}(0.000,0.127)$ $0.571(0.205,0.938)$ $0.857(0.598,1.000)$ $0.875(0.646,1.000)$ $0.200(0.122,0.278)$ $0.017(0.000,0.035)$ $0.038(0.001,0.074)$ $0.103(0.025,0.182)$ $0.167(0.000,0.465)$ $0.333(0.025,0.641)$ $0.062(0.000,0.230)$ $0.500(0.154,0.846)$ $0.333(0.067,0.600)$ $0.265(0.179,0.350)$ $0.667(0.359,0.975)$ $0.167(0.000,0.339)$ $0.442(0.293,0.590)$ $0.033(0.000,0.124)$ $0.043(0.000,0.100)$ $0.500(0.100,0.900)$ $0.065(0.000,0.151)$ $0.667(0.133,1.000)$ $0.022(0.000,0.081)$ $0.062(0.000,0.230)$ $0.250(0.000,0.850)$ $0.013(0.000,0.047)$ $0.500(0.000,1.000)$ $0.019(0.000,0.072)$ $0.300(0.136,0.464)$ $0.500(0.010,0.990)$ $0.455(0.160,0.749)$ $0.600(0.171,1.000)$ $0.500(0.000,1.000)$ $0.250(0.000,0.850)$ $0.667(0.133,1.000)$ $0.028(0.000,0.104)$ $0.333(0.000,0.867)$ $0.500(0.100,0.900)$ $0.333(0.095,0.572)$ $0.015(0.000,0.055)$ $0.800(0.449,1.000)$ $0.364(0.079,0.648)$ $0.167(0.000,0.588)$ $0.167(0.000,0.588)$ $0.750(0.326,1.000)$ $0.167(0.000,0.588)$

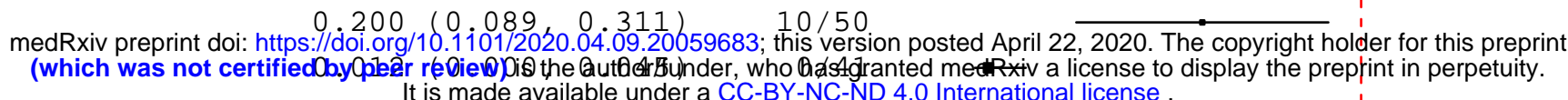

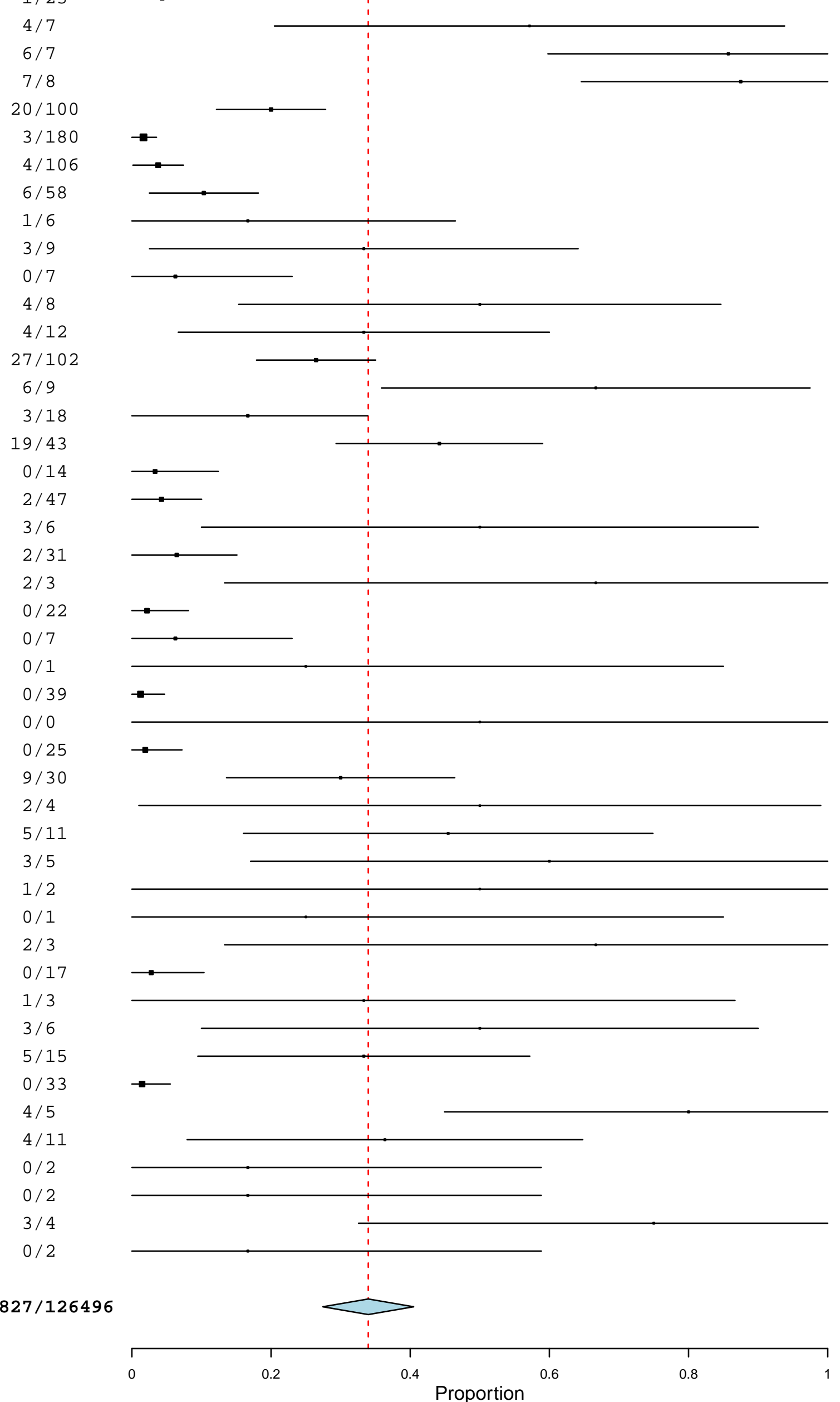




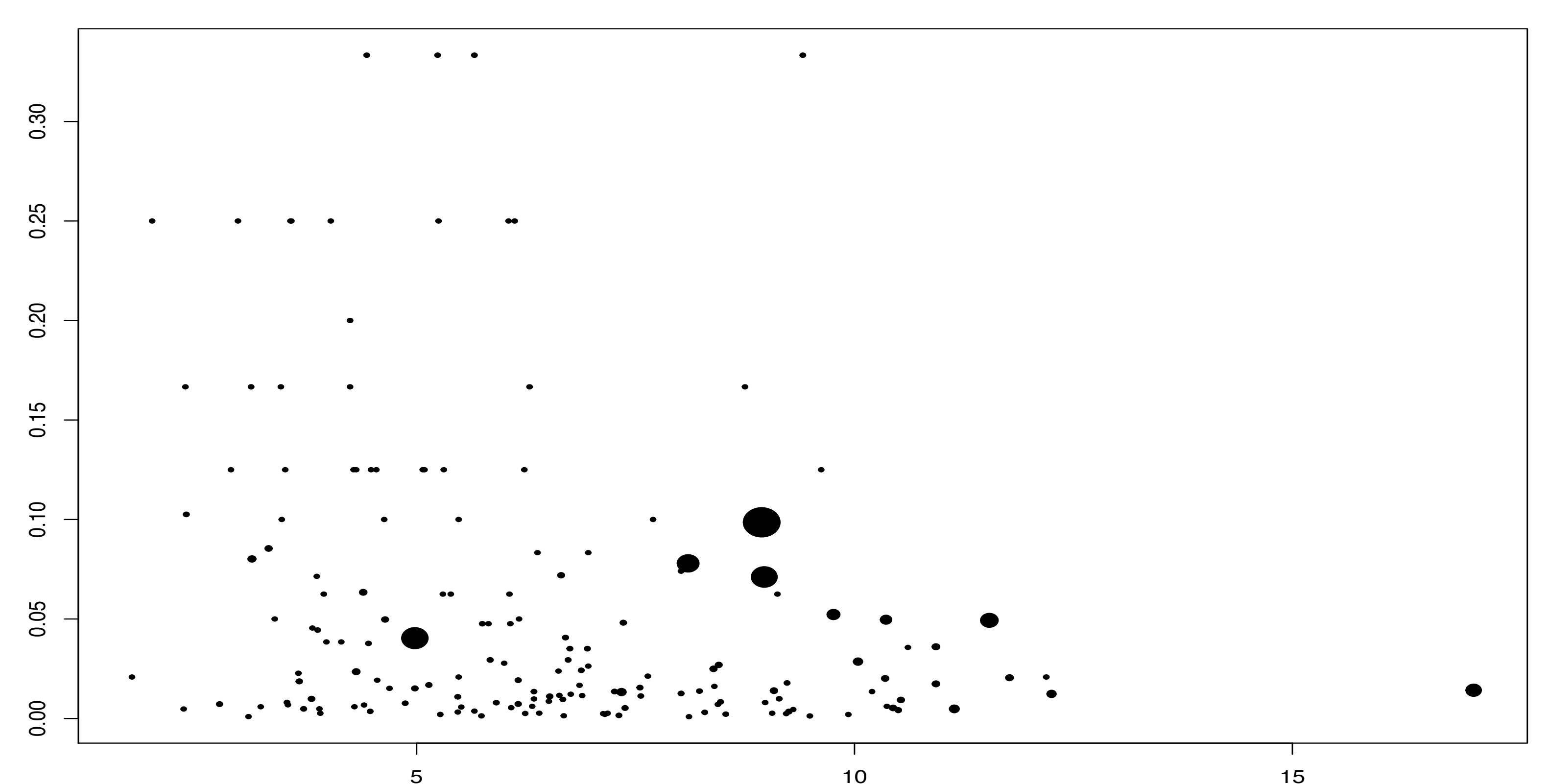

